\title{
COMPARATIVE STUDY ON SOLAR ABSORPANCE OF SOME COATED SURFACES
}

\author{
GAD, H. E. ${ }^{1}$ and SAFYA M. EL-GAYAR ${ }^{2}$ \\ 1. Mechanical Power Engineering Department, Faculty of Engineering, Mansoura \\ University, El-Mansoura 35516, Egypt, E-mail: he_gad@yahoo.com \\ 2. Senior researcher, Agric. Eng. Res. Inst., A. R. C, Giza, P. O. 256, Egypt, - \\ mail:saffy_gyar99@yahoo.com
}

(Manuscript received 4 June 2012)

\begin{abstract}
The effective Absorbance of different surfaces to the total solar radiation flux incident depends mainly on its color. The surface color of buildings, greenhouses, mulchs and absorbing surfaces (solar collectors) affect the amount of absorbed total solar radiation. The surface requires high absorptance for solar radiation when heating is obliged and low Absorbance if heating is not required. To test the absorptance of some coated surfaces an experimental setup to measure the surface temperature is designed and installed at the Thermal laboratory, Mechanical power engineering department, Faculty of Engineering, Mansoura University. Some local paints are used for surface coatings such as blackboard, polish black, white, red, yellow and the natural color of Galvanized iron (G.I.) sheet (gray color). Results have shown graphically that, the plate painted with blackboard paint has the highest temperature and hence the highest absorptance for solar radiation. The next effective Absorbance for solar radiation is achieved by the plates that painted polish black, not painted (gray color) and the red color, respectively. Whereas the lowest effective Absorbance occurred by the surfaces painted white and yellow with glass. The same trends have graphically observed without glass cover. But, there was a drop of plate temperatures and also scattering. While, white coated plate has the lowest temperature and hence the lowest Absorbance for solar radiation.
\end{abstract}

Keywords: Solar Absorbance, Coated Surfaces.

\section{INTRODUCTION}

Since the early 1950s when Tabor (1956) proposed and demonstrated the usefulness of selective surfaces for increasing the photothermal efficiency of solar collectors, many types of absorbers have been reported and produced (Granqvist and Kennedy 1991 ) but only a few became available commercially. One important task to be accomplished concerns the development of optical coatings with very good performances. A novel and affordable solar selective coating exhibiting higher solar absorption efficiency compared to the commercial black paint coating used in most ordinary solar water heating systems has been developed by AlShamaileh (2010). 
Mulch's color affects the temperatures below and above the mulch through the absorption, transmission and reflection of solar energy. This affects the microenvironment surrounding the plants. The degree of contact (thermal contact resistance) between the mulch and the soil also affects soil warming. The better contact the mulch has with the soil the more effective the warming properties of the mulch. Black plastic mulch is the most popular color used in commercial vegetable production especially for weed control. As a blackbody absorber, this plastic absorbs most incident solar radiation, including visible, infrared and ultraviolet light. Much of the thermal energy, however, is lost to the atmosphere through convection and reradiation. Transferring of thermal energy to the soil can be optimized by maximizing mulch contact with the soil. Clear plastic absorbs very little solar radiation.

Water droplets that condense on the underside of clear plastic allow solar light (short-wave radiation) in, but block outgoing long-wave infrared radiation (heat). This heat normally is lost to the atmosphere from bare soil. Incoming solar radiation, however, makes weeds a major problem under clear plastic unless controlled with herbicide or fumigant. Light is reflected back into the atmosphere or the plant canopy from white plastic mulch, resulting in slightly cooler soil temperatures. White plastic mulches can be used to establish crops in the summer, when a reduced soil temperature might be beneficial. Co extruded white on black plastic mulch helps cool the soil (white) while control ling weeds (black). Red plastic mulch has been shown to increase tomato yields and quality in some trials and reduce the severity of early blight in others. It also increases yields of honeydews, muskmelons and zucchini. In addition, it significantly increases soil temperatures. Yellow, orange, blue and gray plastic mulches also have been evaluated. The different radiation patterns that are reflected back into the canopies of various crops from these mulches affect plant growth and development in different ways. Some colors like yellow attract certain insects like green pea aphids and cucumber beetles (Lamont (1999)). Such mulches might be used in a field to grow "catch crops" to pull insects away from other crops.

Solar absorber coatings have attracted a great deal of interest because the efficiency of any solar collector system is strongly dependent on the ability of its absorber to convert solar radiation into heat. The highest photothermal conversion efficiency is to be expected when the coating is able to absorb across most of the solar radiation spectrum $(0.3-2.0 \mu \mathrm{m})$, giving the coating a high solar absorptance ( $\alpha>0: 90$ ) (Niklasson and Granqvist (1991) Unfortunately, losses appear because the heated-up absorber emits energy in the form of thermal radiation $(\lambda>2.0 \mu \mathrm{m})$ although these losses can be reduced by using a coating with a low thermal emittance. 
The European solar thermal market is today dominated by black highly selective ( $\alpha=0.93$ to $0.94, \epsilon=0.04$ to 0.07 ) but expensive thickness sensitive spectrally selective (TSSS) sputtered cermet coatings, such as $\mathrm{TiNO}_{\mathrm{x}}$. A cheaper black TSSS paint coating (Orel et al (1992)) prepared via the coil coating technique is produced by Chromagen but the market is relatively small. However, none of the mentioned coatings is suitable for solar facade absorbers. These coatings are neither mechanically nor corrosion resistant enough to assure the long service life of unglazed solar facade collectors. An additional drawback to the widespread use of solar facades lies in the black appearance of solar absorbers. According to Weiss and Stadler (2002) more than $85 \%$ of architects would prefer colors other than black, even if a lower efficiency would have to be accepted. Accordingly, the main focus of this study was to develop colored selective paint coatings with various hues suitable for unglazed solar absorbers.

Thickness insensitive spectrally selective (TISS) paint coatings represent the material of choice because they combine the advantages of paints (longevity, chemical resistance achieved by a high thickness of the applied layer, variety of colors and simple application) with spectral selectivity, which does not depend on the thermal emittance of the substrate. The latter is achieved by the addition of metallic flakes ( $\mathrm{Al}, \mathrm{Cu}$ and $\mathrm{Ni}$ ) to the paint dispersion significantly decreasing their thermal emittance. The idea of making black TISS paint coatings was first reported by Moore (1985) and Telkes (1997), and since then has been successfully realized by Hoeflaak and Gerrit (1981). His black TISS paint coatings made of black pigment, an organic resin binder and low-emitting aluminum flakes exhibited $\alpha=0.84-0.90$ and $\epsilon=0.41-$ 0.47 .

Optical by Hoeflaak, and Gerrit (1981) Orel et al(2004) Orel et al (2007a) and Orel et al (2007b) and thermal by Kunic et al (2009) properties of ThicknessInsensitive Spectrally Selective (TISS) paint coatings that can be applied onto metal and non-metal surfaces are well documented. The oldest version of TISS paint coatings is a black coating consisting of a black spinel pigment dispersed in silicone or polyurethane resin binders, providing black TISS coatings with solar absorptance $\left(a_{s}\right)$ of about 0.91 (Moore (1985)). Recently, colored TISS paint coatings have also been developed from pigments of various shades imparting TISS coatings with appropriate colors for use as coatings for facade solar absorbers, where aesthetic appearance is important $[13,14]$. Low thermal emittance of black and colored versions of TISS paint coatings is assured by the addition of metallic flake pigment. The lowest $\mathrm{e}_{\mathrm{T}}$ values achieved for both-types of coatings have been $e=0.35-0.41$ (Kunic et al (2009)). 
Recently, Kaluza et al. (2004) developed a black transition metal oxide coatings prepared via the sol-gel route intended to be used as solar absorber coatings in hot water solar collectors and solar facades. The main advantage of the sol-gel deposition of thin films is the ease of their fabrication, since films can be deposited by slowly pulling the substrate from an appropriate colloidal solution and thus avoiding more expensive deposition techniques. Also, the films can be sintered at relatively low temperatures, between $300{ }^{\circ} \mathrm{C}$ and $500{ }^{\circ} \mathrm{C}$ (Hench and West (1990)) and Yi and Sayer (1991)).

In many cases, the need for low price coatings is essential to absorb more solar radiation for buildings, greenhouses and solar collectors. On the other hand, some buildings need to reduce its absorptance for solar radiation. In the present work, an experimental setup is designed and installed to test the absorptance of some coated surfaces to measure the surface temperature. The used paints are of local production.

\section{EXPERIMENTAL SETUP AND PROCEDURE}

The schematic diagram of the experimental setup consists of a wooden box $80 \mathrm{~cm}$ long, $60 \mathrm{~cm}$ wide and a depth of $15 \mathrm{~cm}$ from inside as shown in Fig. 1 . The thickness of the wood plate is $2.4 \mathrm{~cm}$. The box is painted with white from inside and black color from outside to decrease the heat loss. The box is covered with $3 \mathrm{~mm}$ thick glass cover and fixed on an iron frame with an inclination angle of $30^{\circ}$ to horizontal and facing south. A foam insulation layer is fixed from inside with $3 \mathrm{~cm}$ thick on the bottom and $2 \mathrm{~cm}$ on sides. Six $10 \times 10 \mathrm{~cm}$. Galvanized iron G.I sheets of $0.8 \mathrm{~mm}$. thick are fixed in the middle area of the bottom insulation as shown in the same figure. One of these plates is blackboard coated and the other is kept without coating (grey). These two sheets are expected to be the reference plates for the maximum and minimum absorptance, respectively. The other four sheets are painted polished black, red, yellow and white coated. All sheets are fixed in a $2 \mathrm{~mm}$. deep depression in the back insulation.

The setup is instrumented to measure the six G.I sheet temperatures at centers, inner glass surface, outside box bottom temperatures and the ambient air temperature. The total solar radiation data are also measured and recorded at 10 minutes intervals.

The solar radiation data are measured with a solar power meter TES1333 with the following specifications:

Display:

Range :

Resolution:
3-1/2 digits Maximum indication 1999

$$
2000 \mathrm{~W} / \mathrm{m}^{2}
$$

$1 \mathrm{~W} / \mathrm{m}^{2}$ 
Spectral response:

400-1100 $\mu \mathrm{m}$

Accuracy Typically within $\pm 10 \mathrm{~W} / \mathrm{m}^{2}$ or $\pm 5 \%$, whichever is greater in sunlight;

Additional temperature induced error:

Angular accuracy:

$60^{\circ}$

Sampling Time:

Manu data memory and read :

Auto data memory:

Operating temperature and humidity

$$
\pm 0.38 \mathrm{~W} / \mathrm{m}^{2} /{ }^{\circ} \mathrm{C} \text { from } 25 \text { Celsius }
$$

Cosine corrected $<5 \%$ for angles $<$
Approx. 0.4 second

99 sets

32000 sets

$0{ }^{\circ} \mathrm{C}$ to $50{ }^{\circ} \mathrm{C}$ below $80 \% \mathrm{RH}$

The experimental work is carried out on the roof of the Thermal engineering laboratory, Mechanical power department, Faculty of Engineering, Mansoura University, latitude $31.05^{\circ} \mathrm{N}$ and longitude $31.365^{\circ} \mathrm{E}$. The experiments were performed during different days from December (2010) to June (2011) on sunny days. The coatings are produced according to the Egyptian standard specifications No. 793 class 2. Factory: New Borg El Arab city second industrial zone, Alex. Film thickness: $50-60 \mu \mathrm{m}$ dry film per single coat.

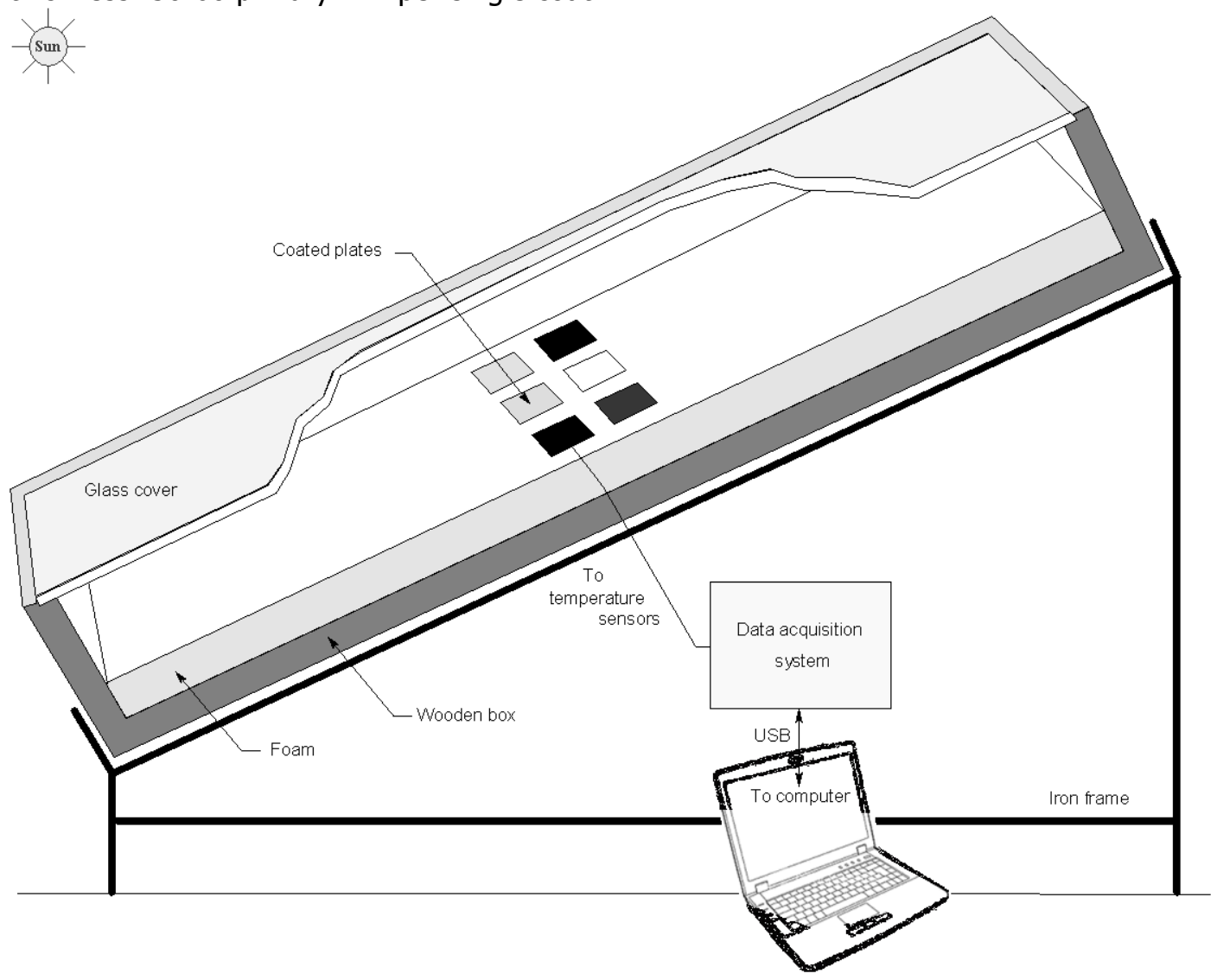

Fig. 1 The experimental setup.

Fig. 2 shows a block diagram of the data acquisition circuit which is used also for monitoring and sending the measured temperatures from the system to the computer. The main component of the circuit is the PIC18F2455, which it is a 
universal serial bus (USB) microcontroller form Microchip Company. This microcontroller has been chosen since it provides the capability of connecting it to the computer via a USB (version 2.0) interface. The USB 2.0 is a high speed serial interface that provides a communication speed up to $12 \mathrm{Mb} / \mathrm{s}$, making it the most suitable interface for transferring high speed data between the computer and the microcontroller (Jan Axelson (2009)). On the other hand, this microcontroller has a large numbers of $A / D$ converter channels (up to 10 channels with a 10 bit resolution) to convert the analog signals from the temperature sensors into a digital form. However, only eight channels have been used for the temperature sensors. Additionally, the internal memory size of this microcontroller (24 KB program memory and $2 \mathrm{~KB}$ data memory) and its processing power are high making it the most suitable device for monitoring and recording the system information in real time PIC (2007). Moreover, it is readily available in the market with a low cost compared to the digital signal processors.

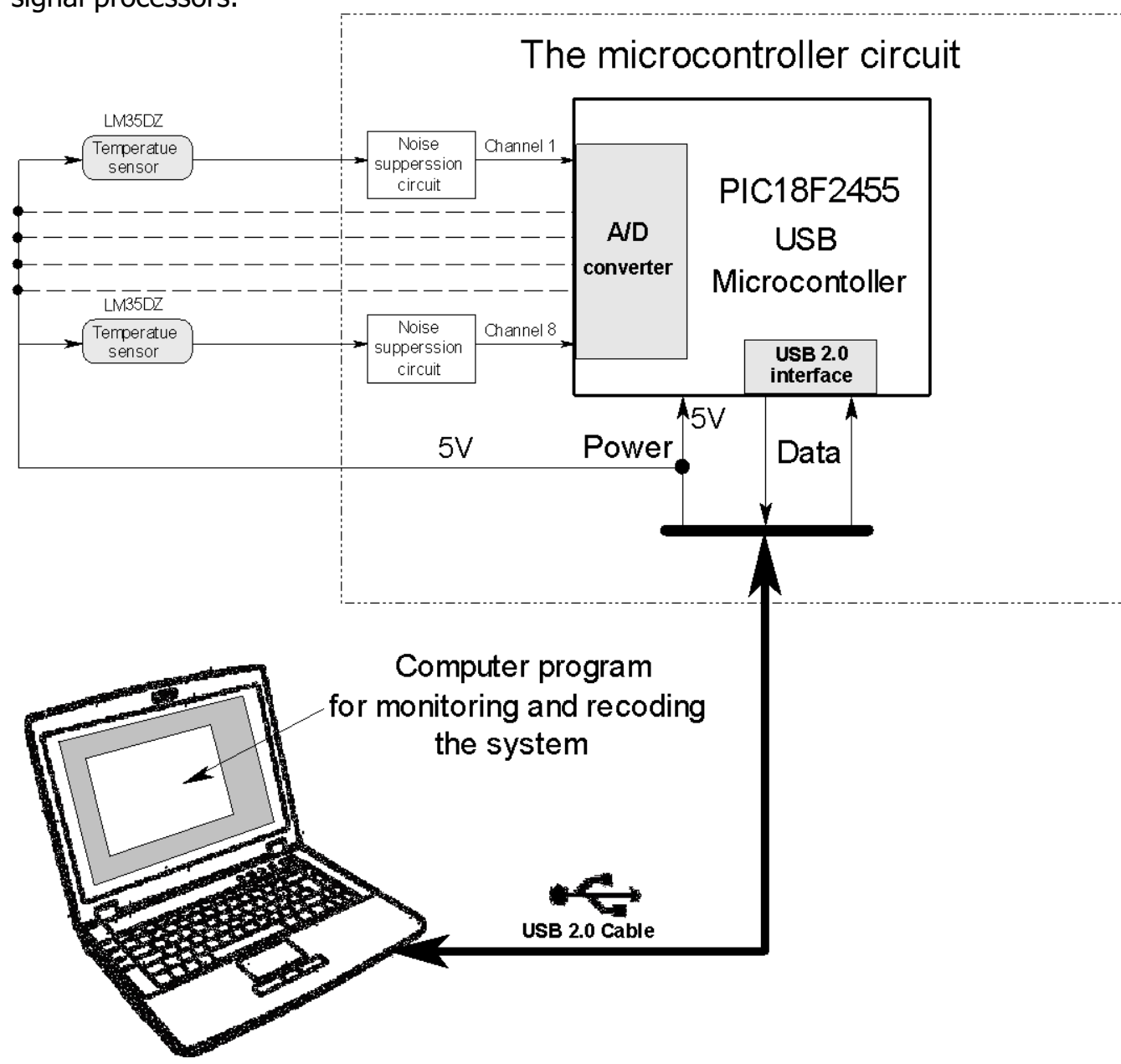

Fig. 2 A block diagram of the data acquisition system.

The temperature sensor is LM35DZ from National Semiconductor, which is a high precision integrated circuit temperature sensor. The output voltage of this sensor is linearly proportional to the Celsius temperature. The LM35DZ sensor does not 
require any external calibration. Also, it provide a typical accuracies of $\pm 0.25{ }^{\circ} \mathrm{C}$ at room temperature and $\pm 0.75{ }^{\circ} \mathrm{C}$ over a full -55 to $+150^{\circ} \mathrm{C}$ temperature range. Moreover, this sensor has a very low self-heating, which it is less than $0.1^{\circ} \mathrm{C}$ in stagnant air LM (2000). However, a noise suppression circuit must be added to the output of each sensor to reduce the effect of the electromagnetic noise from AC and DC sources as shown in the same figure.

The nine temperature sensors are fixed in the experimental setup, one is fixed to measure the inner glass cover temperature, the second is fixed to measure the outer box bottom temperature and the third sensor is fixed under the setup to measure the ambient air temperature. The other six sensors are fixed to measure the different coated G.I sheet temperatures at centers. The sampling rate of recorded data is adjusted via the computer program by 10 minutes. Fig. 3 shows a photograph of the setup where the computer and control circuit are fixed in the shadow under the solar box. The solar radiation is measured at the upper face of the apparatus via a solar meter. For a stable operation, the microcontroller must work in a moderate ambient temperature.

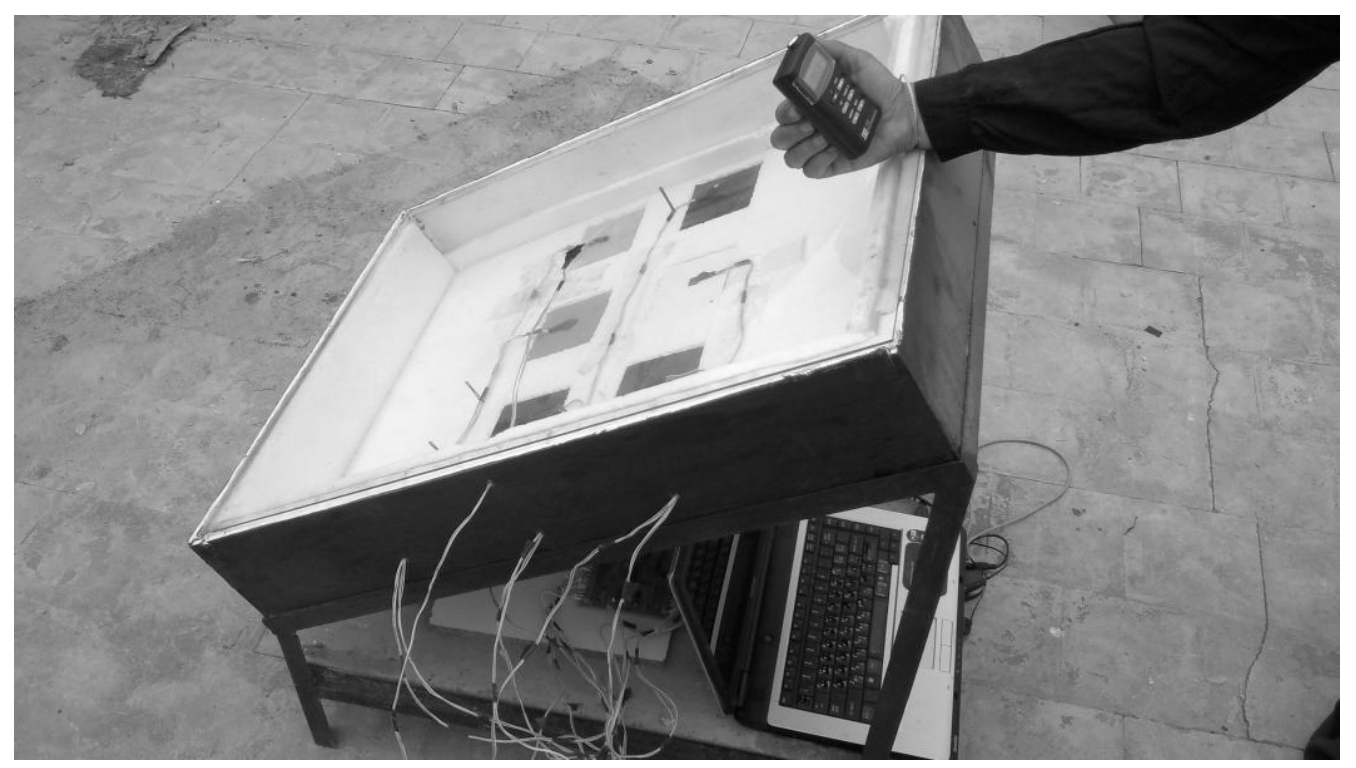

Fig. 3 A photograph of the experimental setup.

\section{RESULTS AND DISCUSSION}

If a solar radiation beam with intensity $(\mathrm{H})$ hits the coated sheet as shown in Fig. 4, a part of the beam $(H \rho)$ is reflected back to space and the other is absorbed and consumed to heat up the sheet $(\mathrm{H} \alpha)$ such that, 


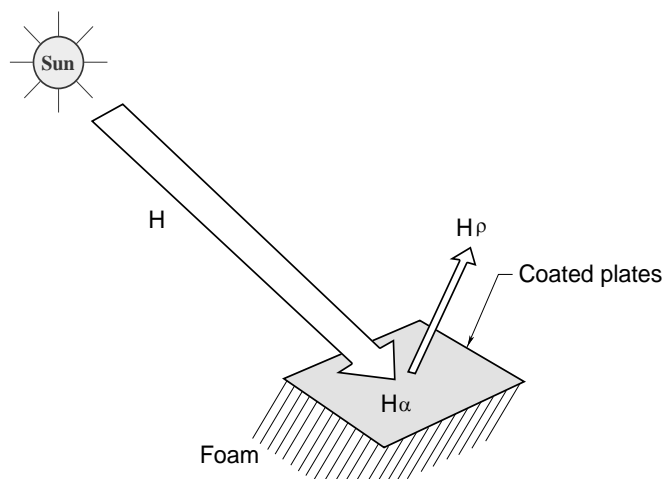

Figure 4 Solar radiation beam hitting a coated plate.

$$
\mathrm{H}=\mathrm{H} \alpha+\mathrm{H} \rho+\mathrm{Q}_{\text {Loss }}
$$

Neglecting the heat losses $Q_{\text {Loss }}$ from the top and bottom since it is almost the same for all the sheets,

$$
1.0=\alpha+\rho
$$

Where, $\mathrm{H}$ is the solar radiation beam $\left(\mathrm{W} / \mathrm{m}^{2}\right)$,

QLoss is heat losses $\left(\mathrm{W} / \mathrm{m}^{2}\right)$,

$\alpha$ is the sheet absorptance and

$\rho$ is the sheet reflectance.

Equation (2) indicates that decreasing the reflectance $(\rho)$ means increasing the absorptance $(\alpha)$ and hence in increasing the plate temperature and vice versa.

Fig. 5 shows the temperature of each plate as a function of time in one day (29/12/2010). All temperatures increase with time to a maximum value around noon and then decrease again. The ambient air temperature is shown to be the lowest temperature with a maximum value between 12 noon and 13 p.m as shown in the figures from 5 to 11 . The box bottom temperature starts in the morning less than the ambient temperature and then increases by few degrees above the ambient temperature (in the range of $5{ }^{\circ} \mathrm{C}$ approximately).

The highest temperature recorded as expected is the plate with blackboard paint as shown in these figures. It is clear that the blackboard paint has the highest absorptance for solar radiation. From the other side, yellow paint plate has the lowest temperature and hence the lowest absorptance for solar radiation (expect in one day (23/1/2011) white paint plate has the lowest temperature). After that, the white color as expected comes close to that of yellow.

The polish black color comes next to the blackboard plate in the temperature and hence the absorptance for solar radiation. The G.I. plate without color (grey) sometimes comes higher and lower than that of polish black paint plate. The red color plate comes lower to the two blacks and grey plates. The glass cover temperature comes in between the plates as shown in these figures. 


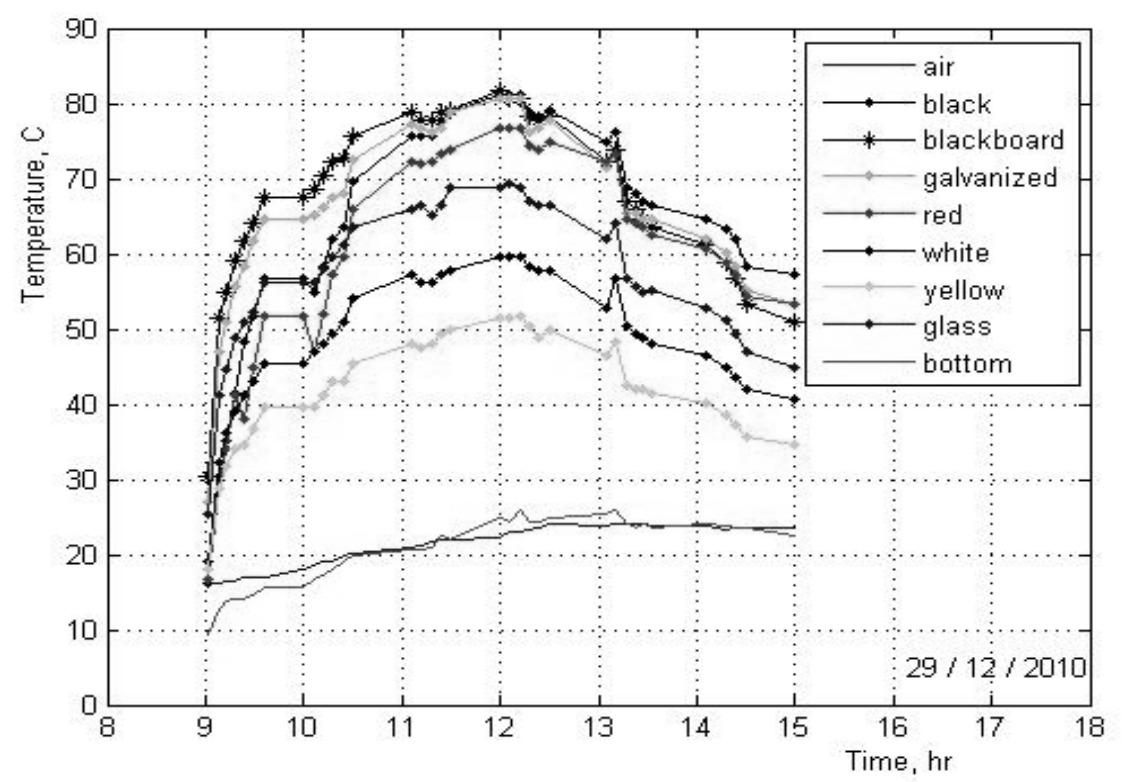

Fig. 5 Temperature of different sheets with time. (Glass cover)

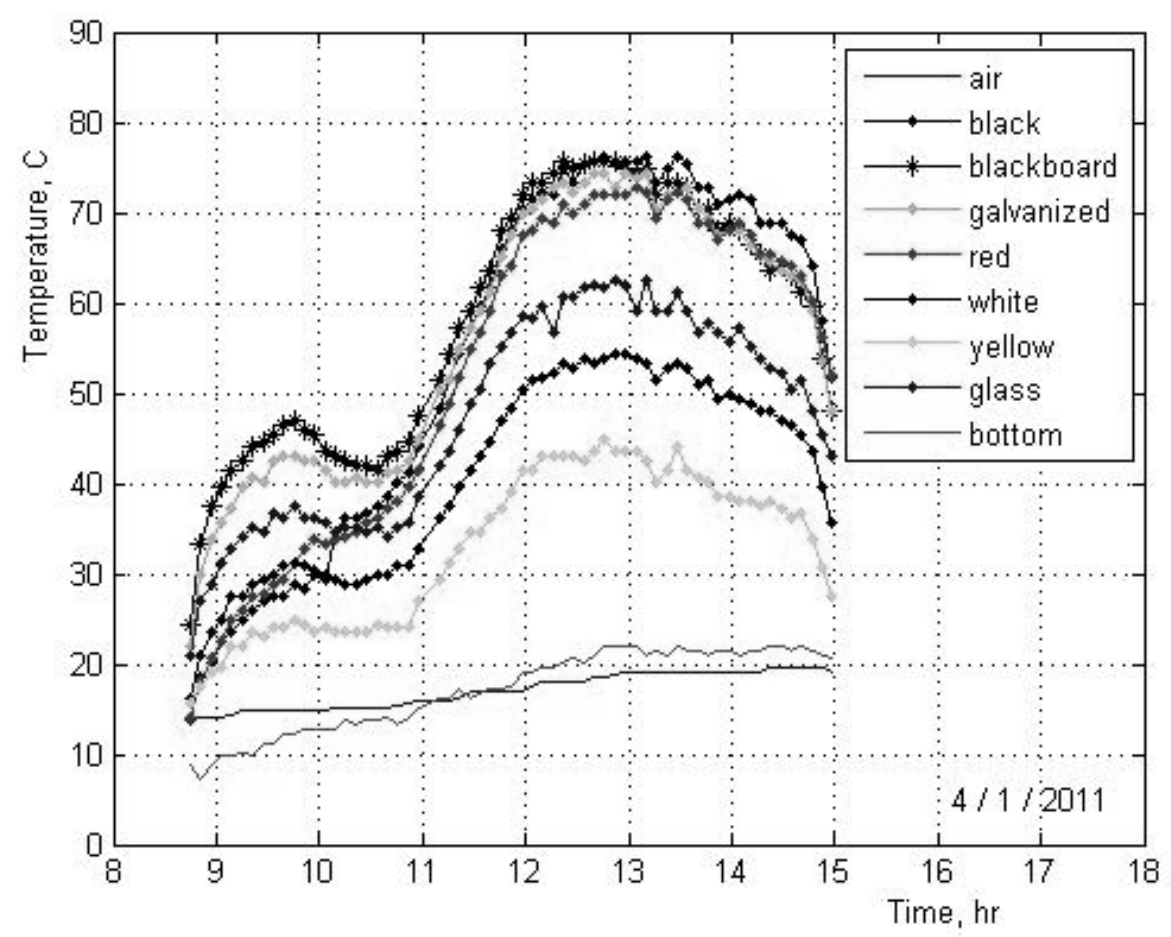

Fig. 6 Temperature of different sheets with time. (Glass cover) 


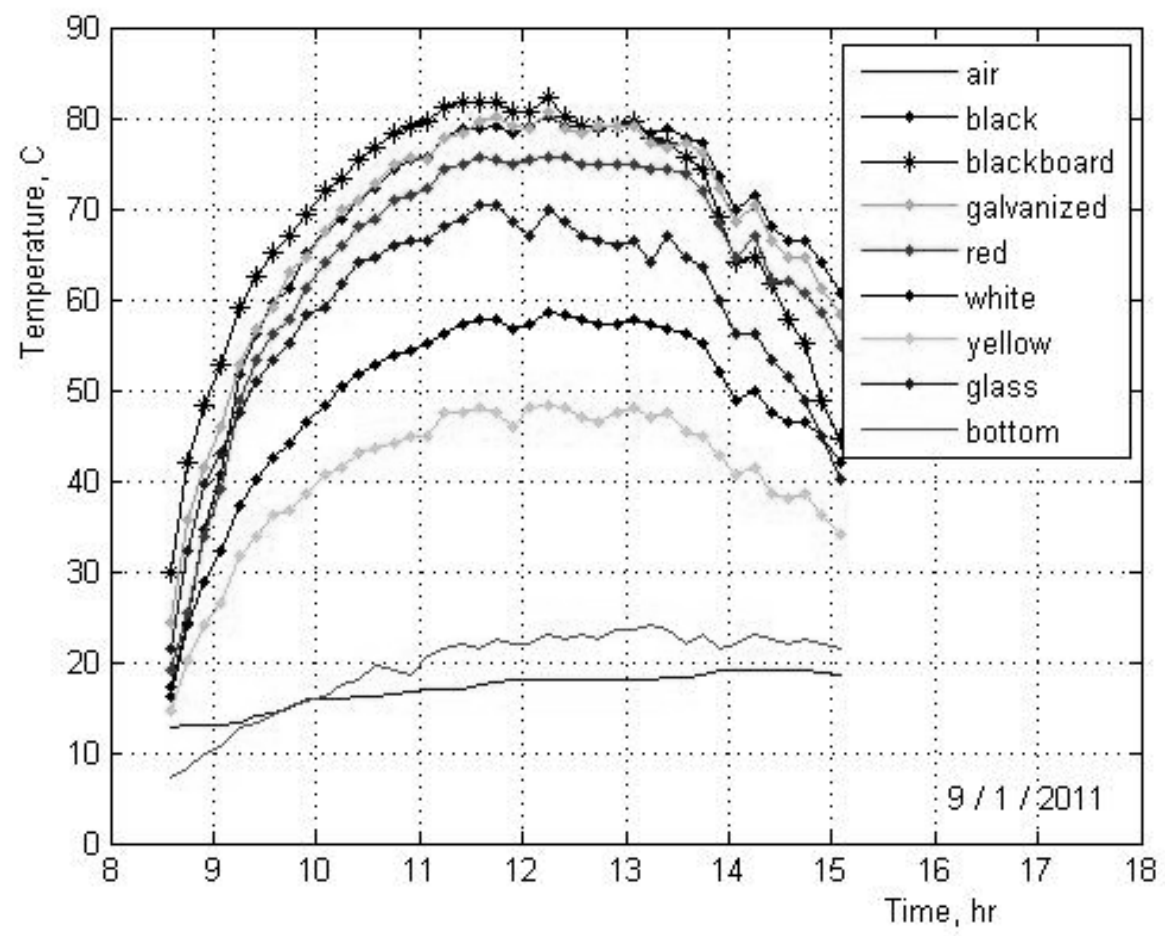

Fig. 7 Temperature of different sheets with time. (Glass cover)

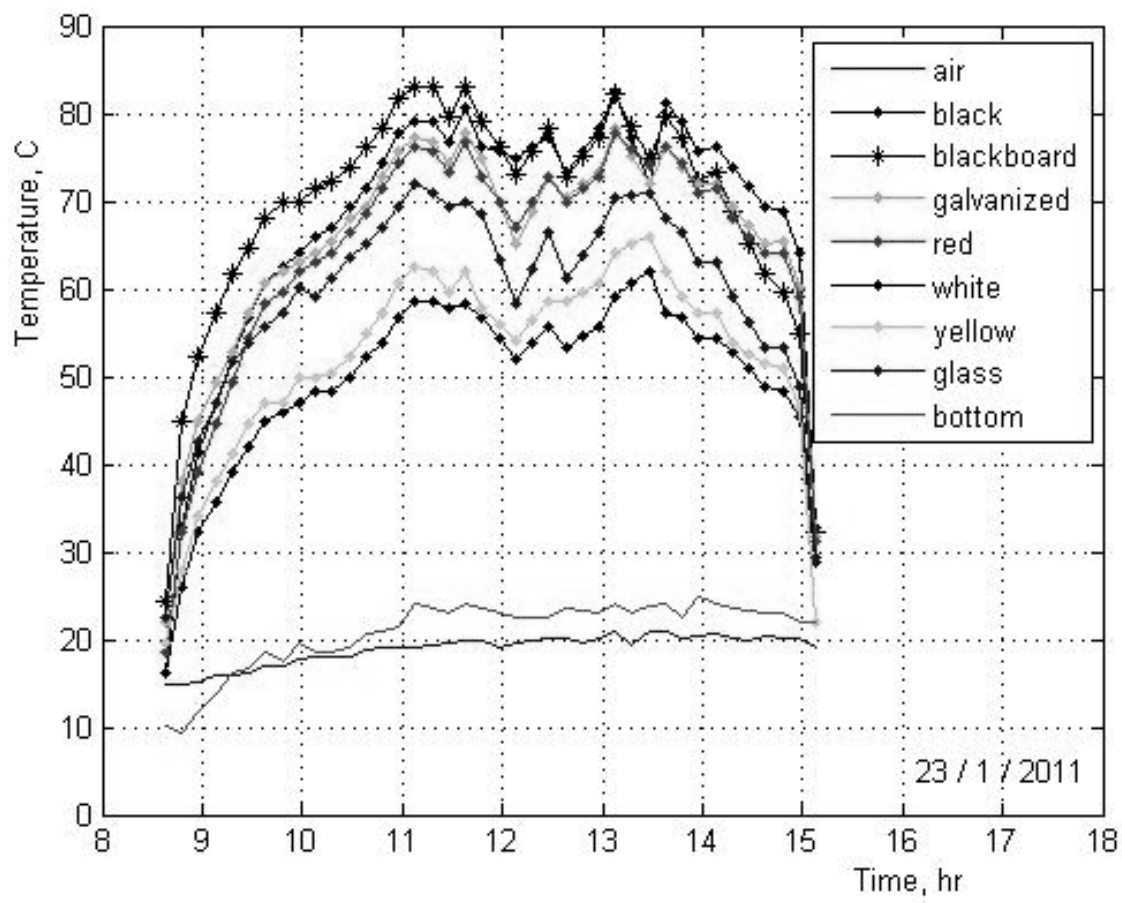

Fig. 8 Temperature of different sheets with time. (Glass cover) 


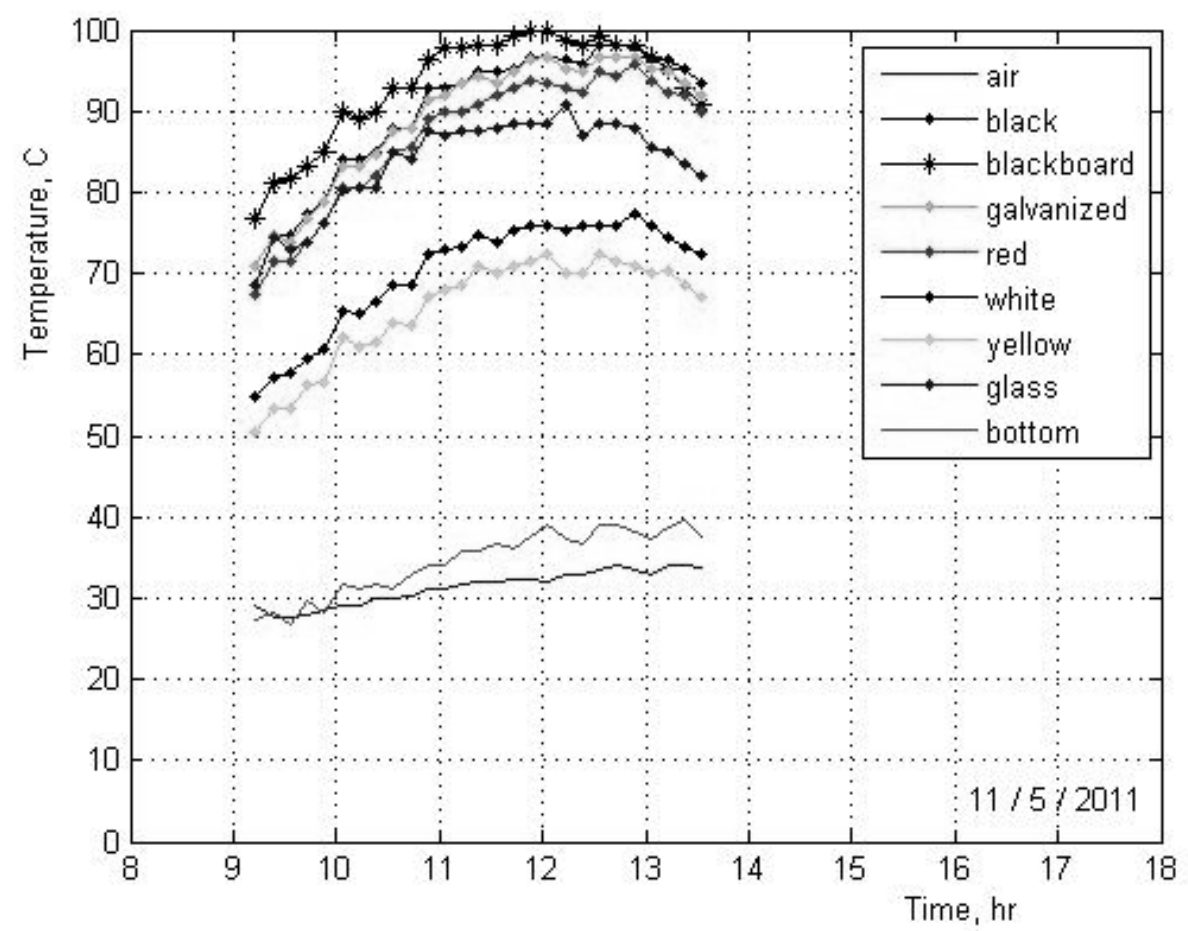

Fig. 9 Temperature of different sheets with time. (Glass cover)

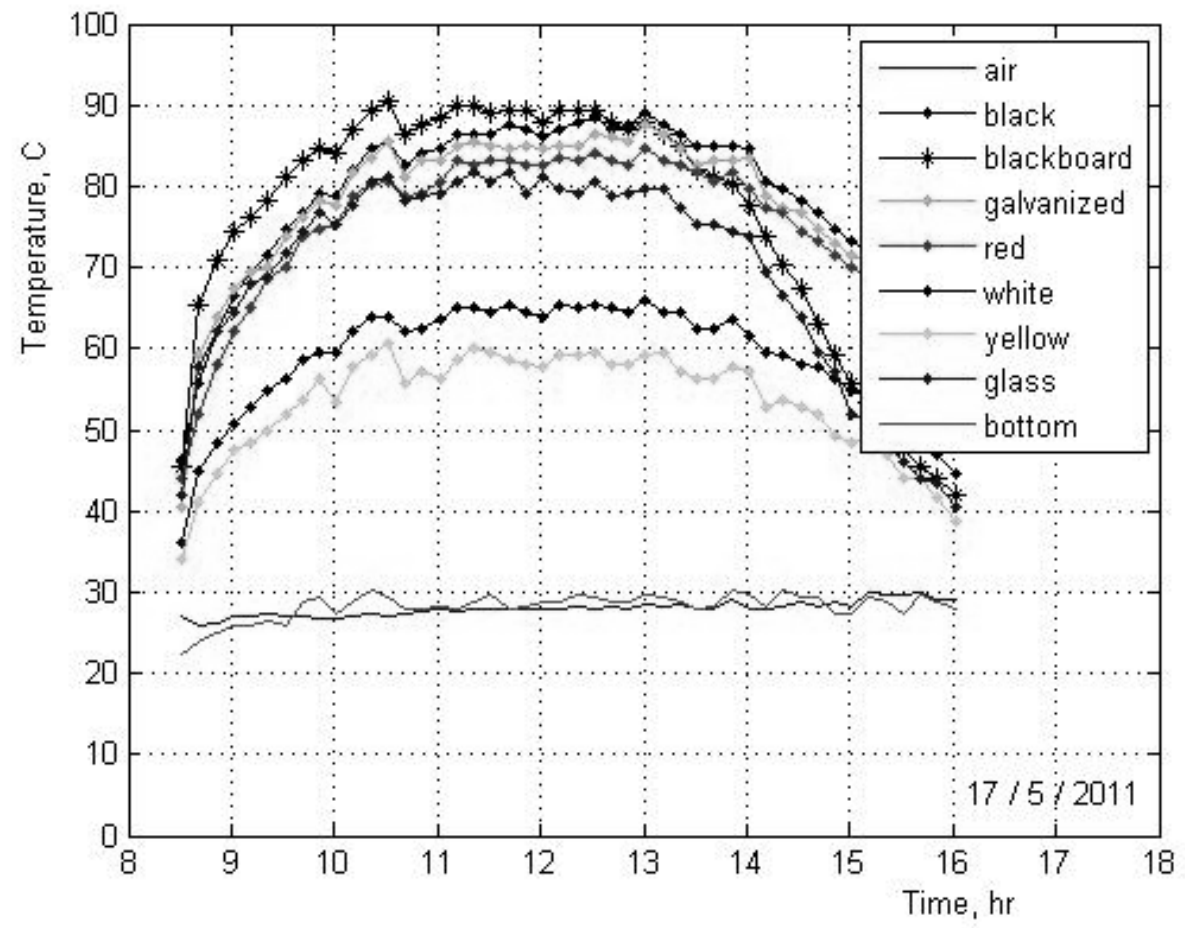

Fig. 10 Temperature of different sheets with time. (Glass cover) 


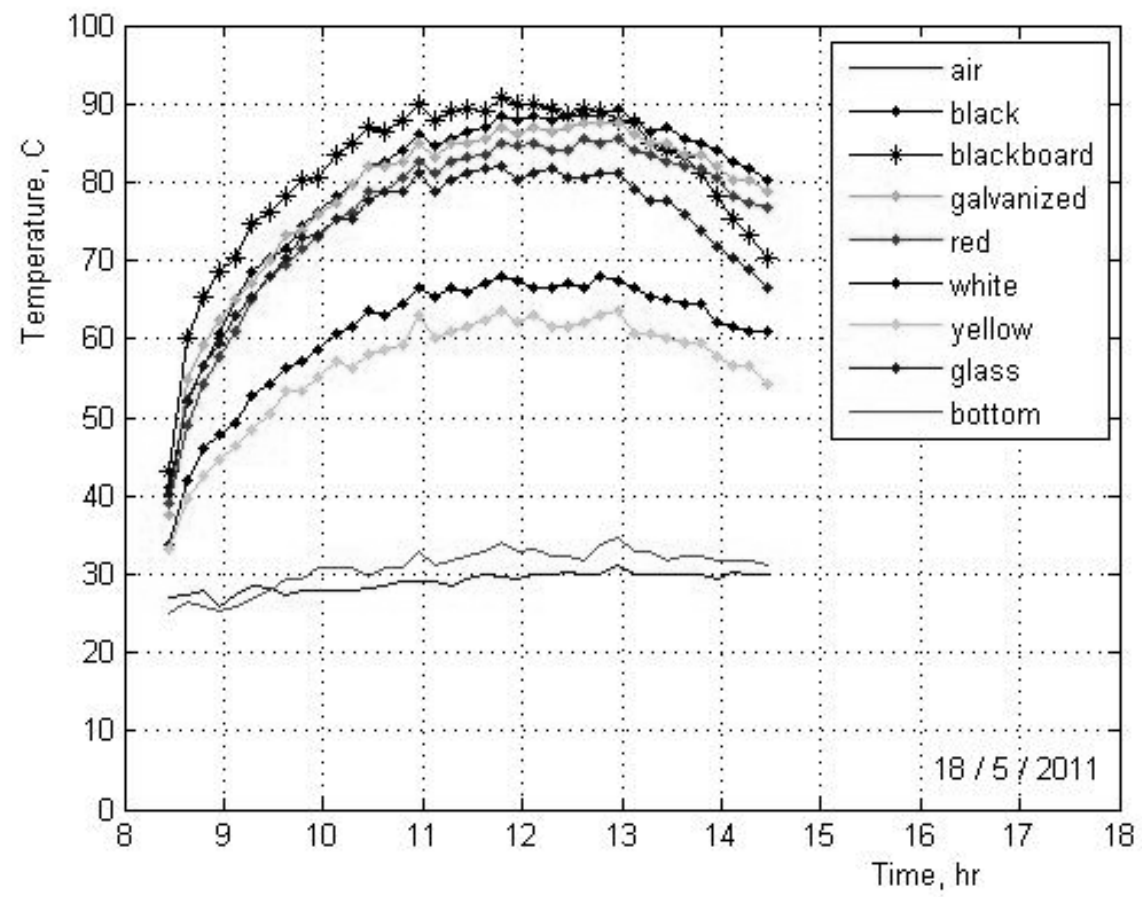

Fig. 11 Temperature of different sheets with time. (Glass cover)

Figures from 12 to 15 show the same results without glass cover. Because of the wind effects, there was a drop of plate temperatures and also scattering. However, the same trend of temperatures of colored plates is observed.

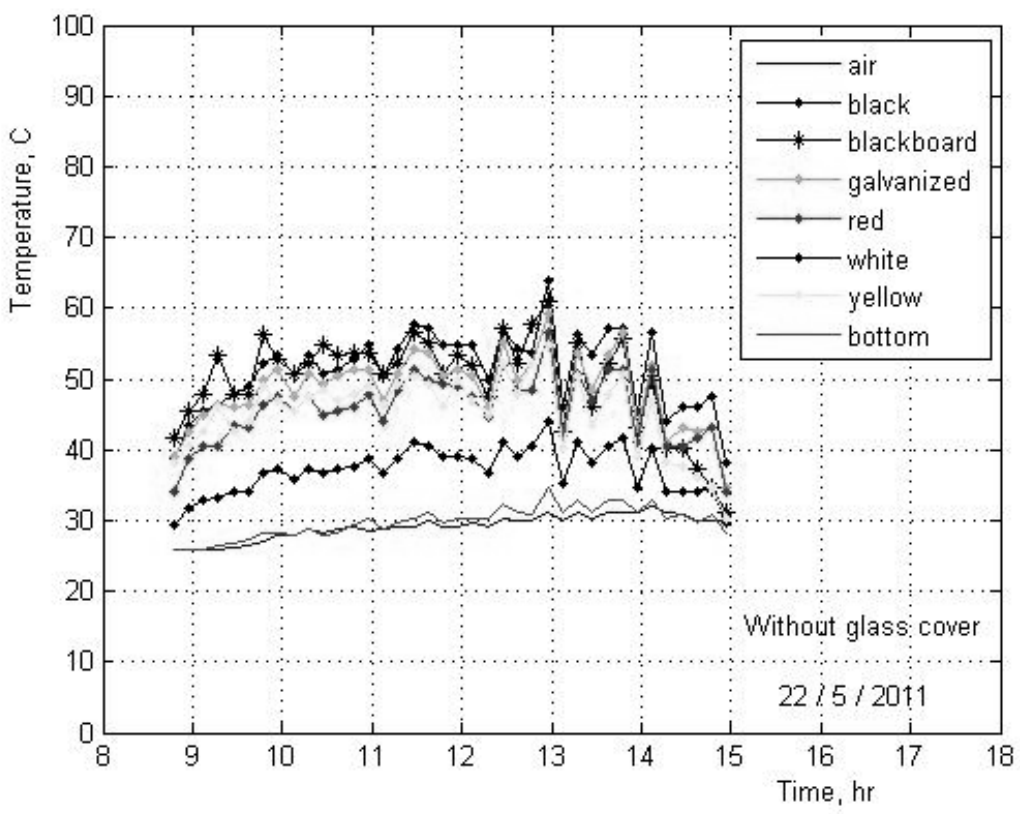

Fig. 12 Temperature of different sheets with time. (Without glass cover) 


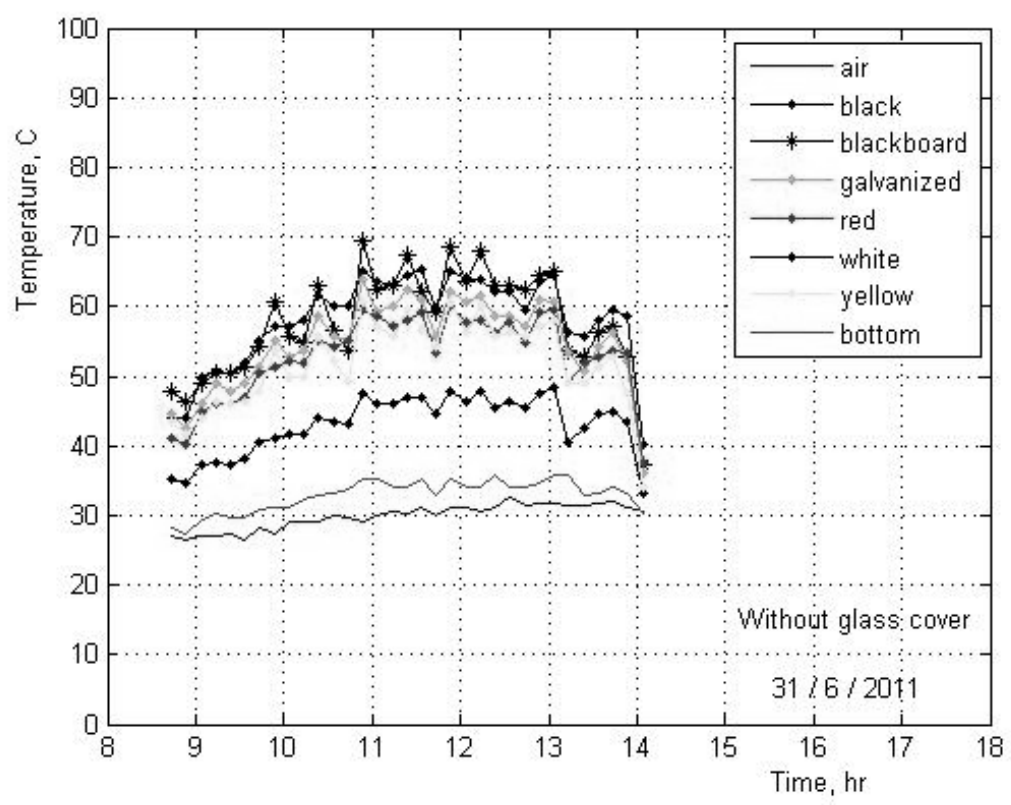

Fig. 13 Temperature of different sheets with time.(Without glass cover)

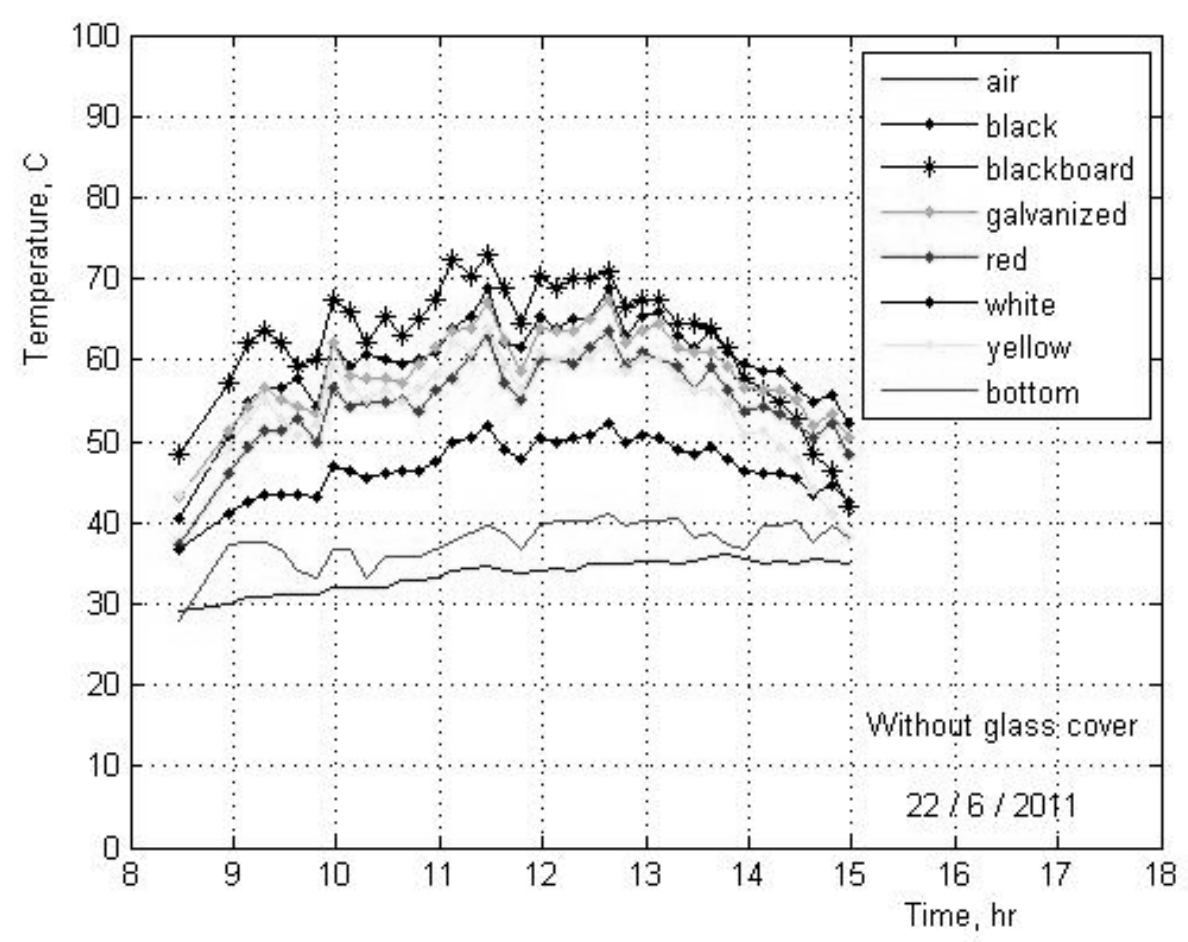

Fig.14 Temperature of different sheets with time. (Without glass cover) 


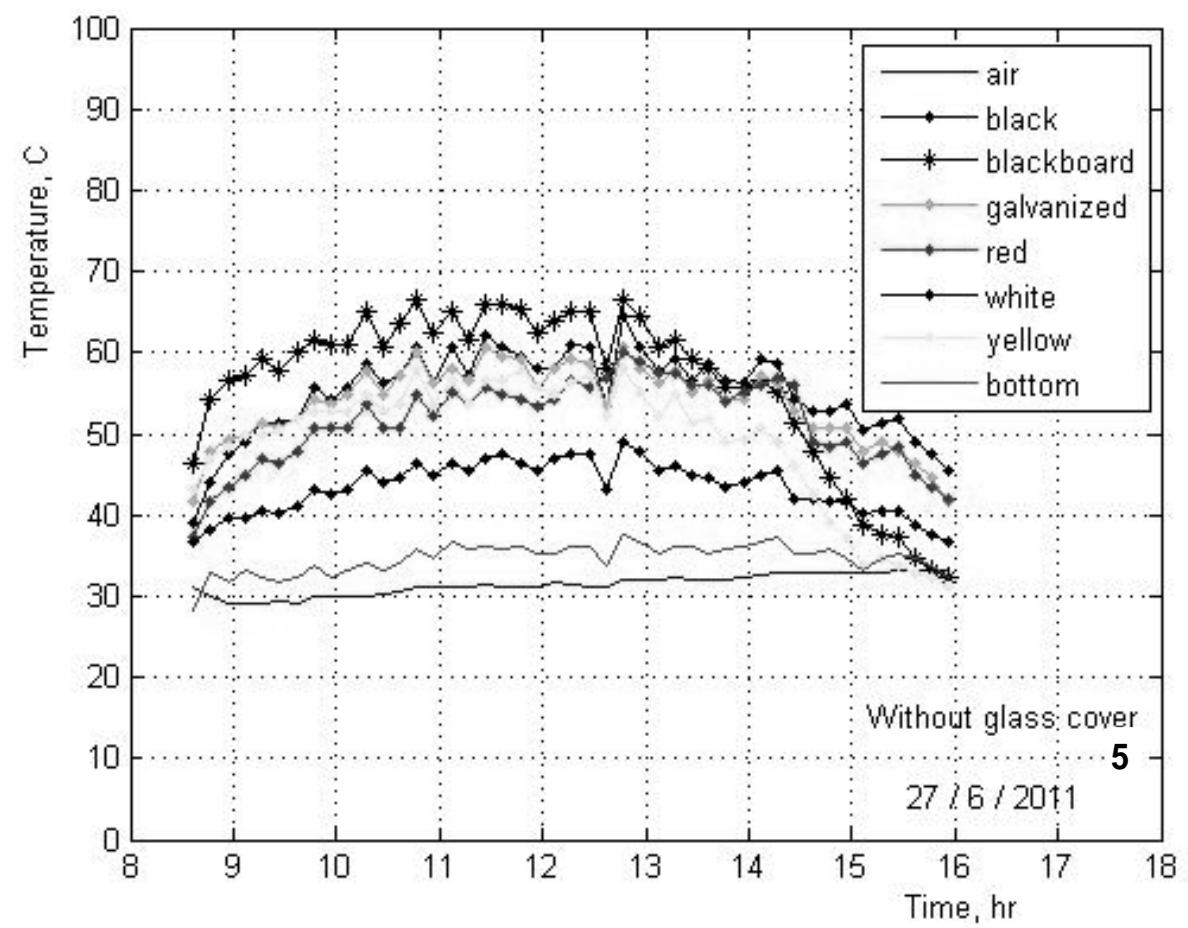

Fig. 15 Temperature of different sheets with time. (Without glass cover)

While, white coated plate has the lowest temperature and hence the lowest absorptance for solar radiation. Moreover, yellow paint sheet sometimes comes higher and lower than that of red paint sheet. In addition, the box bottom temperature was greater than the ambient temperature as revealed in the previous figures.

The total solar radiation data measured on tilted surface ( $30^{\circ}$ facing south) in some experimental days are shown in Fig. 16. It was noticed that, the peak of the global solar radiation intensity was achieved at med-day (at 12 noon) as cleared in this figure. 
GAD, H. E. and SAFYA M. EL-GAYAR
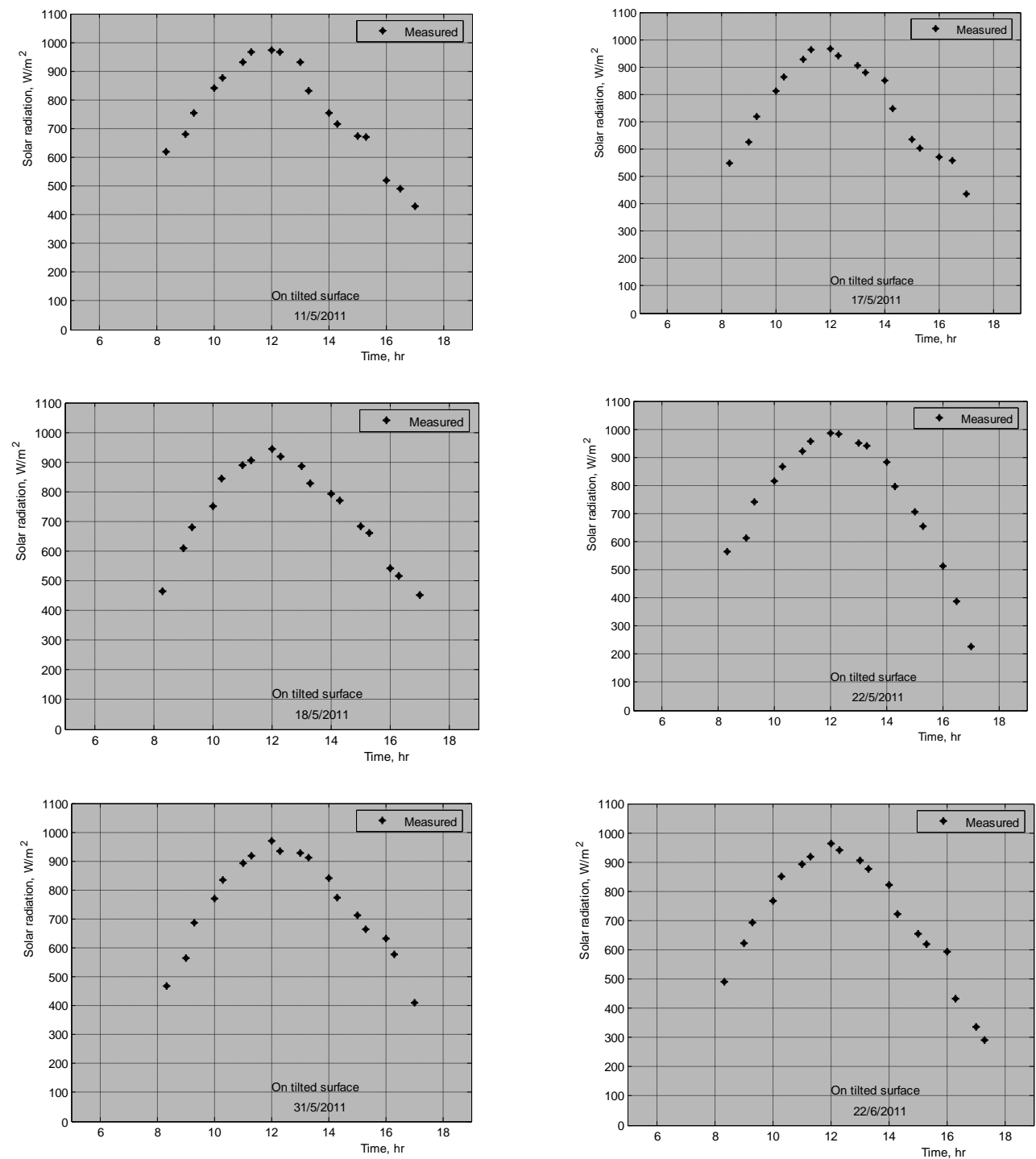

Fig. 16 Total solar radiation measured on tilted surface $\left(30^{\circ}\right.$ facing south) in some experimental days.

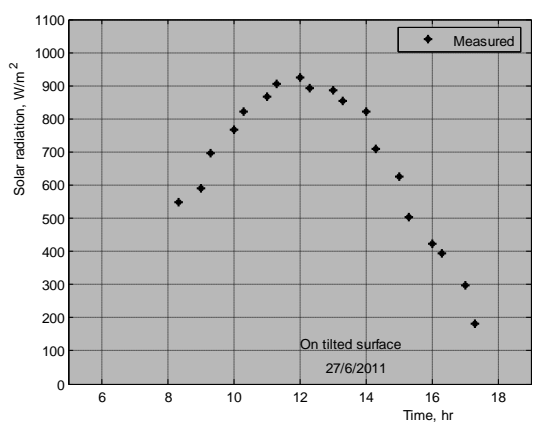




\section{CONCLUSIONS}

The absorptance of different surfaces to the total solar radiation depends mainly on its color. The surface requires high absorptance when heating is required and low absorptance if heating is not obliged. To test the absorptance of some coated surfaces an experimental setup to measure the surface temperature is designed and installed at the Thermal laboratory, Mechanical power engineering department, Faculty of Engineering, Mansoura University. Some local paints are used for surface coatings such as blackboard, polish black, white, red, yellow and the natural color of Galvanized iron (G.I.) sheet (gray color). Results have shown graphically that the plate painted by blackboard paint has the highest temperature and hence the absorptance for solar radiation. The next effective (absorptance for solar radiation) is achieved by the plates the painted polish black, not painted (gray color) and the red color respectively. The plates painted white and yellow come in the least (absorptance for solar radiation) with glass cover. The same trend have shown graphically without glass cover. But, there was a drop of plate temperatures (about 75\%) and also scattering. White coated plate has the lowest temperature and hence the lowest absorptance for solar radiation.

\section{REFERENCES}

1. AlShamaileh, E. "Testing of a new solar coating for solar water heating applications "Solar Energy 84 2010. 1637-1643.

2. Granqvist C.G. (Ed.), "Materials Science for Solar Energy Conversion Systems" Pergamon Press, Oxford, 1991.

3. Hench, L.L., and J.K. West " Chem. Rew" 90 1990. 33.

4. Hoeflaak, M.,and J. Gerrit, Patent DE3105936 1981.

5. Jan Axelson, "USB Complete", Lakeview Research, Forth edition,2009.

6. Kaluza, L., A. Surca, B. Orel, G. Drazi e, and P. Pelicon, J. Sol-gel Sci. Techn., submitted for publication 2004.

7. Kennedy, C.E. "Review of mid-to-high temperature solar selective absorber materials", Technical Report, NREL/TP-520- 31267, http://www.osti.gov/ / bridge.

8. Kunic R., M. Kozelj, B. Orel, A.S. Vuk, A. Vilcnik, L.S. Perse, D. Merlini, S. Brunold," Adhesion and thermal stability of thickness insensitive spectrally selective (TISS) polyurethane-based paint coatings on copper substrates" Sol. Energy Mater. Sol. Cells 93 (5) 2009. 
9. Lamont, W. J.. "The use of different colored mulches for yield and earliness". Proceedings of the New England Vegetable and Berry Growers Conference and Trade Show, Sturbridge, Mass. 1999 p. 299-302.

10. LM35DZ datasheet, "National Semiconductor" Nov. 2000.

11. Moore, S.W. " Solar absorber selective paint research" Sol. Energy Mater. 12 (6) 1985. 435-447.

12. Niklasson, G.A., and C.G. Granqvist, "Selectively solar-absorbing surface coatings", optical properties and degradation" in: C.G. Granqvist (Ed.), Materials Science for Solar Energy Conversion Systems, in: A.A.M. Sayigh (Ed.), Renewable Energy Series, Pergamon Press, Oxford, 1991.

13. Orel, B., Z. Crnjak Orel, N. Leskovsek, and M. Klanjsek Gunde," Surf. Coat". Int. 75 1992. 488.

14. Orel, B. , A.S. Vuk, H. Spreizer, D. Merlini, and M. Vodlan, "Spektralno selektivni premazi za absorberje $\mathrm{v}$ soncnih zbiralnikih, Slovenia Patent SI21510 (A), 2004.

15. Orel, B., H. Spreizer, L.S. Perse, M. Fir, A. S. Vuk, D. Merlini, M. Vodlan, and M. Kohl, "Silicone-based thickness insensitive Spectrally selective (TISS) paints as selective paint coatings for Coloured solar absorbers (Part I)" Sol. Energy Mater. Sol. Cells 91 (2-3) 2007a. 93-107.

16. Orel, B. H. Spreizer, A.S. Vuk, M. Fir, D. Merlini, M. Vodlan, M. Kohl "Selective paint coatings for coloured solar absorbers: Polyurethane thickness insensitive spectrally selective (TISS) paints (Part II)" Sol. Energy Mater. Sol. Cells 91 (23) (2007b) 108-119.

17. PIC18F2455 datasheet, "Microchip Technology "Inc., 2007.

18. Tabor, H. "Transactions of the Conference on the Use of Solar Energy", vol.11, Part I, Section A1-23, University of Arizona Press, Tucson, 1956.

19. Telkes, M. US Patent 4.011.190 1997.

20. Weiss, W., and I. Stadler, in: "Proceedings of the Industry Workshop of the IEA Solar Heating and Cooling Programme", Task 26, IEA, Delft, 2002.

21. Yi, G. and M. Sayer, "Ceramic Bull" 70 (7) 1991. 1173. 


\title{
نتائج مقارنة الامتصاصية الثمسية لبعض الاسطح المطلية
}

\author{
حلى السيد جاد1 ، صفية مصطفى الجيار 2 \\ 1 \\ 2 معهُ بحوث الهندسة الزراعية - مركز البحوث الزرراعية - الدقى - مصر.
}

تعتمد قدرة امتصاص الأسطح المختلفة للإشعاع الثمسى الكلى بصفة أساسية على لون السطح.

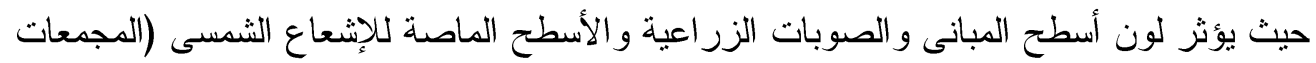

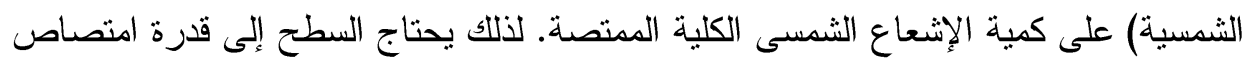

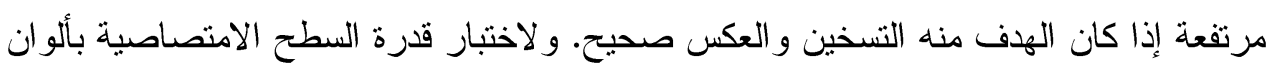

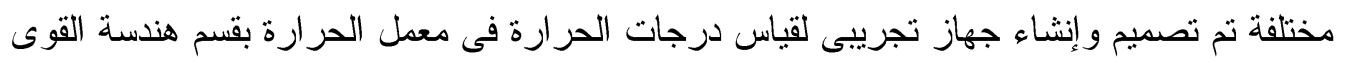

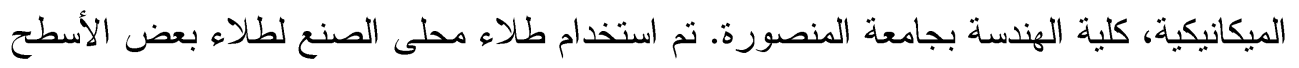

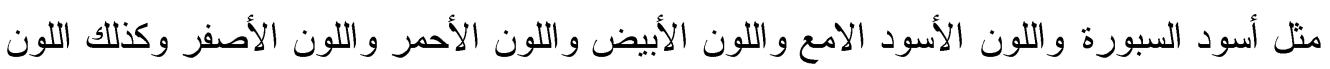

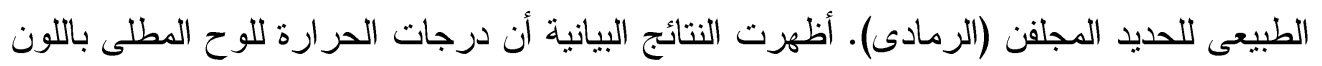

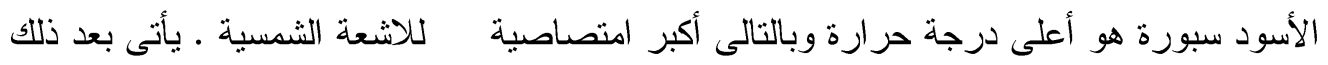

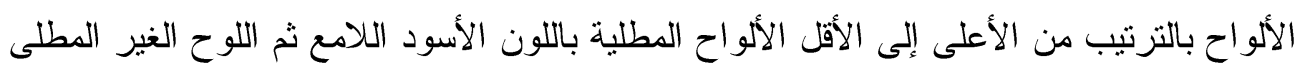

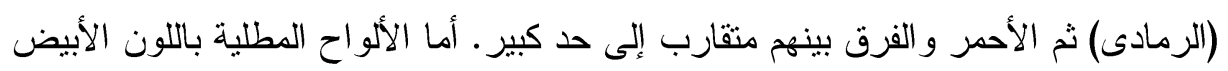

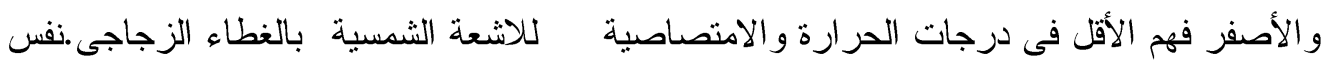

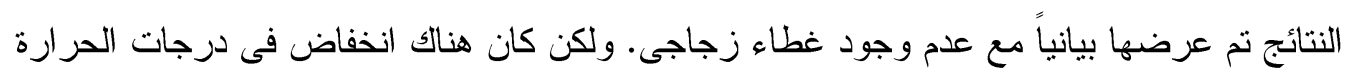

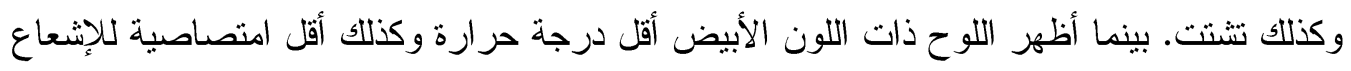

